\title{
The determination of copper in biological materials by flame spectrophotometry
}

\author{
G. E. NEWMAN AND M. RYAN \\ From the Nuffield Department of Clinical Biochemistry, Radcliffe Infirmary, Oxford
}

SYNOPSIS A method for the determination of the copper content of biological materials by flame spectrophotometry is described. The effects of interference by ions such as sodium and phosphate were eliminated by isolating copper as the dithizonate in $\mathrm{CCl}_{4}$. Results obtained for the urinary excretion of copper by a patient with Wilson's disease before and after treatment with penicillamine are reported.

Recently, flame photometry has largely replaced chemical methods for the determination of sodium and potassium in biological materials. With improvements in the design and sensitivity of instruments the technique is now being applied to the determination of calcium, magnesium, and other metals. A number of reviews of the design and application of flame photometers have been published, e.g., that by Margoshes and Vallee (1956).

Clinical laboratories are frequently requested to determine certain trace elements, an example being the measurement of copper in urine in the diagnosis and treatment of Wilson's disease. Usually trace metal analysis requires special techniques which are not always readily available.

Copper ions, when introduced into a flame of sufficient temperature to excite them, emit radiation at a characteristic wavelength of $324.7 \mathrm{~m} \mu$ (Margoshes and Vallee, 1956). It should be possible, therefore, for any laboratory equipped with a flame spectrophotometer of appropriate sensitivity to measure copper. One of the problems associated with the direct determination of copper in biological materials by flame photometry is the interference encountered from ions such as phosphate and sodium, which are usually present in much greater quantities. If, however, copper can be extracted quantitatively from the medium containing interfering ions it can then be measured under standard conditions.

In the method described here, copper was extracted from biological materials, prepared for analysis by wet-ashing, into a solution of dithizone (diphenylthiocarbazone) in carbon tetrachloride. The copper was then transferred to an aqueous phase by oxidiz-

\footnotetext{
Received for publication 4 October 1961.
}

ing the copper dithizonate and excess dithizone with a solution of potassium permanganate, and measured with a Unicam S.P. 900 flame spectrophotometer.

\section{MATERIALS}

Metal-free water and analytical grade reagents were used throughout.

REAGENTS The following were used:-

Concentrated $\mathrm{H}_{2} \mathrm{SO}_{4}, \mathrm{HNO}_{3}$, ammonia solution (S.G. $0.88)$.

$8 \mathrm{M}-\mathrm{H}_{2} \mathrm{O}_{2}$ (prepared from $30 \% \mathrm{w} / \mathrm{v} \mathrm{H}_{2} \mathrm{O}_{2}$ ).

$\mathrm{KMnO}_{4}$ solution $\left(0.015 \mathrm{M}\right.$ in $\left.0 \cdot 1 \mathrm{~N}-\mathrm{H}_{2} \mathrm{SO}_{4}\right)$.

$\mathrm{KI}$ solution $\left(10 \mathrm{~g} .1100 \mathrm{ml} . \mathrm{H}_{2} \mathrm{O}\right.$ saturated with $\left.\mathrm{SO}_{2}\right)$ The $\mathrm{SO}_{2}$ was present to reduce any substance likely to oxidise dithizone.

Dithizone solution $\left(50 \mu \mathrm{g} . / \mathrm{ml}\right.$. $\left.\mathrm{CCl}_{4}\right)$.

Alkaline citrate solution This was prepared by dissolving $500 \mathrm{~g}$. citric acid monohydrate and $5 \mathrm{mg}$. phenol red in $500 \mathrm{ml} . \mathrm{H}_{2} \mathrm{O}$, adding concentrated $\mathrm{NH}_{4} \mathrm{OH}$ until the colour of the indicator changed to red, and diluting to 1 litre with $\mathrm{H}_{2} \mathrm{O}$. Contaminating metals were removed from this solution by extracting with dithizone solution.

Copper solution The primary standard was a solution of copper sulphate in $2 \mathrm{~N}_{-} \mathrm{H}_{2} \mathrm{SO}_{4}$, containing $0.01 \mathrm{~g}$. copper/ml., prepared from spectrographically standardized copper oxide (Johnson, Matthey and Co. Ltd.). Working standards were prepared by diluting portions of the primary standard with $\mathrm{H}_{2} \mathrm{O}$ and adding $\mathrm{H}_{2} \mathrm{SO}_{4}$ so that the final concentration of acid was $0 \cdot 1 \mathrm{~N}$.

GLASSWARE Only Pyrex or hard borosilicate glassware was used and precautions were taken to prevent contamination of reagents and specimens during storage and analysis (Butler and Newman, 1956).

Urine was collected in polythene containers. 


\section{EXPERIMENTAL}

A Unicam S.P. 900 flame spectrophotometer burning an acetylene-air mixture was used. A compressor was employed to supply air at a pressure of $2 \mathrm{~kg} . / \mathrm{cm} .^{2}$ and an oil vapour filter was fitted between the compressor and the photometer. Acetylene was obtained from a cylinder through a regulator valve and the manometric control on the photometer to indicate acetylene pressure was adjusted to read $15 \mathrm{~cm}$. At a wavelength of $324.7 \mathrm{~m} \mu$ with the photomultiplier in position, a slit-width of $0.08 \mathrm{~mm}$. and with the electrical bandwidth control at 4, the electronic gain and the galvanometer zero controls set at about 5 and 6 respectively, a standard curve for solutions of copper was obtained by measuring the galvanometer deflection (Fig. 1). Alternatively, a standard type potentiometric recorder (Honeywell) was used to measure the emission. Recordings were obtained by scanning the wavelength scale from 326.5 to $322 \mathrm{~m} \mu$.

The standard deviation was $\pm 3 \%$ for concentrations of copper up to $5 \mu \mathrm{g} . / \mathrm{ml}$. and the minimum concentration that could be measured to within twice the standard deviation was $1 \mu \mathrm{g}$. copper $/ \mathrm{ml}$. Smaller concentrations of copper could be detected with this instrument if the electronic gain setting was increased, but, in general, the higher the gain setting the greater the instability.

Portions of urine (25 to $250 \mathrm{ml}$.), whole blood, or plasma $(5$ to $10 \mathrm{ml}$.) were prepared for analysis by wetashing with concentrated $\mathrm{H}_{2} \mathrm{SO}_{4}(5$ or $10 \mathrm{ml}$.) and concentrated $\mathrm{HNO}_{3}(10$ or $20 \mathrm{ml}$.) in digestion flasks of $500 \mathrm{ml}$. capacity. The flasks were heated until the nitric

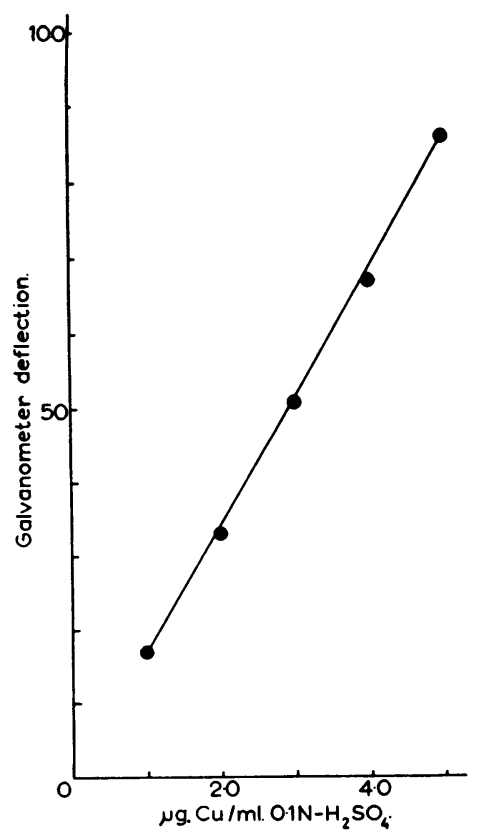

FIG. 1. Standard curve for copper (mean values). acid was boiled off. If necessary a few drops of $8 \mathrm{M}-\mathrm{H}_{2} \mathrm{O}_{2}$ were added from time to time to complete oxidation. Varying amounts of white solid, probably sulphates and phosphates of metals such as calcium, usually formed in the completed digests and this precipitate must be dissolved before the extraction of copper is attempted since it may adsorb some of the metal. Solution was achieved by warming with alkaline citrate solution. The digest was diluted with $10 \mathrm{ml} . \mathrm{H}_{2} \mathrm{O}$, then $5 \mathrm{ml}$. alkaline citrate solution was added and the mixture adjusted to $p \mathrm{H} 8.5$ (as judged by the red colour of the indicator) with concentrated ammonia solution (S.G. 0.88). During this procedure the contents of the flask were mixed well and sufficient heat was generated to dissolve any solid matter. Water was added to adjust the final volume to $50 \mathrm{ml}$. The time taken to complete the digestion and neutralization process was usually six hours.

Copper reacts with dithizone in acid solution and in this way can be separated from a number of metals which may be present, e.g., lead and zinc (Butler, 1952). Mercury, bismuth, and silver are co-extracted with copper from acid solution but the amounts usually present in biological materials do not interfere with the measurement of copper by flame spectrophotometry. The extraction of copper is less tedious if competition for dithizone by other metals is avoided. In contrast to copper, the extraction of mercury and bismuth can be partially inhibited by the presence of $0.5 \mathrm{~g} . \mathrm{KI} / 100 \mathrm{ml}$. aqueous phase (Butler, 1952). The neutralized digest was adjusted to $p \mathrm{H} 3$ with concentrated $\mathrm{H}_{2} \mathrm{SO}_{4}$ or concentrated $\mathrm{HCl}$ using methyl yellow as indicator. When cool, an appropriate quantity of KI solution was added and the solution transferred to a separating funnel of $150 \mathrm{ml}$. capacity. The flask was rinsed with two successive $10 \mathrm{ml}$. portions of water. Copper was extracted by shaking with successive 5 or $10 \mathrm{ml}$. portions of dithizone solution until the green colour of the reagent was unchanged. Shaking was performed mechanically for periods of 10 min. at a rate of 200 shakes $/ \mathrm{min}$. and the extracts were pooled in a separating funnel. The time taken for the extraction process was one to two hours depending upon the amount of copper present.

The isolated copper was transferred to an aqueous phase suitable for flame photometry by shaking the 을 pooled extracts by hand with $\mathrm{KMnO}_{4}$ solution. Sufficient permanganate solution (usually 4 to $15 \mathrm{ml}$.) was used to 0 oxidize the copper dithizonate and excess dithizone. Usually, considerable quantities of insoluble oxidation $N$ and reduction products of dithizone and permanganate were formed and it was found that copper was adsorbed on this precipitate. As much as possible of the organic $\omega$ phase was discarded and then $1 \mathrm{ml} .8 \mathrm{M}-\mathrm{H}_{2} \mathrm{O}_{2}$ was added $\sigma$ to the aqueous phase, mixing well immediately after the addition. In this way the precipitate was dissolved, a clear aqueous phase was obtained, and a satisfactory $\stackrel{\infty}{-}$ separation of the organic phase achieved. If necessary the aqueous phase was diluted with $0 \cdot 1 \quad \mathrm{~N}-\mathrm{H}_{2} \mathrm{SO}_{4}$ to $\overline{0}$ obtain a concentration of copper suitable for analysis, $\overrightarrow{\mathbb{D}}$ and the copper content of the solution determined with $\stackrel{?}{+}$ the flame spectrophotometer. Reagent blanks and copper $\varrho$ standards were included with each batch of analyses. The $\bar{\gamma}$ instrument settings already described were standardized 
except for minor adjustments to the electronic gain and galvanometer zero controls. The precision of the method was such that the standard deviation of the method, calculated from 10 duplicate recoveries of various amounts of copper added to the digestion stage so that the final concentration of copper measured was 1 to $5 \mu \mathrm{g} . / \mathrm{ml}$. aqueous phase, was $\pm 3 \%$.

\section{RESULTS AND DISCUSSION}

Some of the constituents of biological materials interfere with the direct determination of copper by flame spectrophotometry. For example, the variable quantities of sodium and phosphate found in human urine (usually 2 to $4 \mathrm{~g}$. sodium/l. and the equivalent of 0.03 to $0.09 \mathrm{~N}-\mathrm{H}_{3} \mathrm{PO}_{4}$ ) affect the measurement of copper. Examples of this interference are shown in Fig. 2. Each recording represents $3 \mu \mathrm{g}$. copper $/ \mathrm{ml}$. $0 \cdot 1 \mathrm{~N}_{-} \mathrm{H}_{2} \mathrm{SO}_{4}$. Solution (a) contained no additional ions, but the other solutions contained (b) 0.04 $\mathrm{N}-\mathrm{HCl}$, (c) $0.04 \mathrm{~N}-\mathrm{NaCl}$ (2 g. sodium/1.), (d) 0.03 $\mathrm{N}-\mathrm{H}_{3} \mathrm{PO}_{4}$, (e) $0.04 \mathrm{~N}-\mathrm{NaCl}$ and $0.03 \mathrm{~N}-\mathrm{H}_{3} \mathrm{PO}_{4}$.

Solutions $(b)$ and $(c)$ contained the same concentration of chloride ions but (c) also contained an equivalent amount of sodium. The presence of sodium $(c)$ increased the background radiation and altered the shape of the copper recording. Phosphate ions not only increased the background but altered the shape of the copper recording to a different extent $(d)$. These effects were cumulative $(e)$ and in fact the electronic gain and galvanometer zero controls had to be altered to such an extent to obtain these recordings that the sensitivity of the method was decreased about threefold. By wet-ashing and extracting the copper with an organic phase containing dithizone, the effects of such interference were eliminated and the isolated copper was measured under standard, reproducible conditions. The reaction products of the $\mathrm{KMnO}_{4}$ used in the aqueous phase did not affect the measurement of copper as judged by comparison between the standard curve for copper in $0.1 \mathrm{~N}_{-} \mathrm{H}_{2} \mathrm{SO}_{4}$ (Fig. 1) and recovery experiments.

The quantity of copper that could be determined accurately was limited by the sensitivity of the flame photometer and by the final volume of aqueous phase required for analysis. In the method described here, the minimum volume of aqueous phase required was 1 or $5 \mathrm{ml}$. (with a minimum concentration of $1 \mu \mathrm{g}$. copper $/ \mathrm{ml}$.) depending upon whether the radiation emitted by the copper was measured with a galvanometer or a recorder. The quantity of dithizone solution required to extract this amount of copper was such that the error of the method was increased if the oxidative aqueous phase was less than $5 \mathrm{ml}$., probably due to inefficient phase separation. The minimum copper content of the material

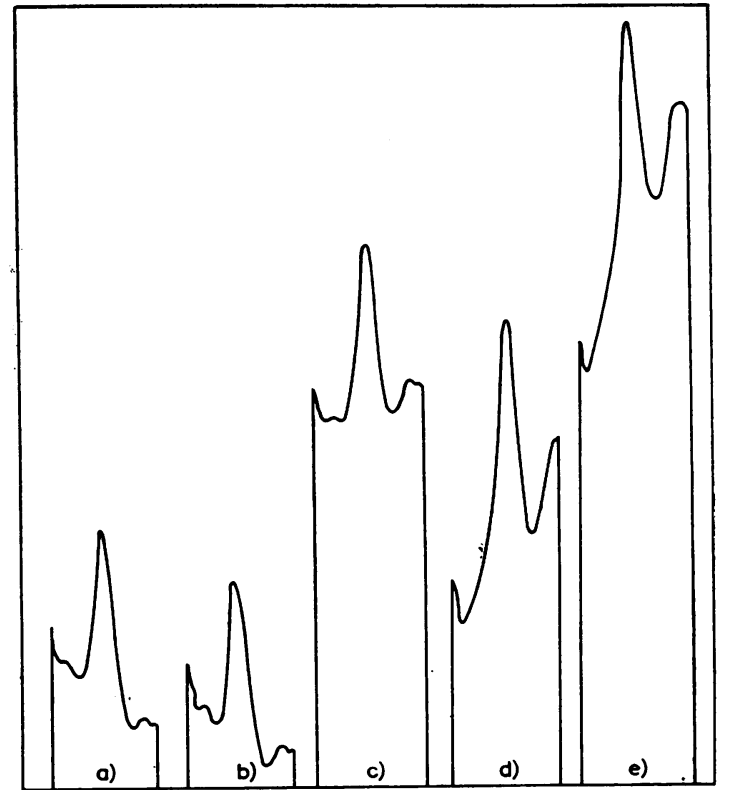

FIG. 2. The effect of chloride, sodium, and phosphate ions on the measurement of copper.

a $3 \mu \mathrm{g} . \mathrm{Cu} / \mathrm{ml} .0 \cdot 1 \mathrm{~N}-\mathrm{H}_{2} \mathrm{SO}_{4}$.

b $3 \mu \mathrm{g}$. $\mathrm{Cu} / \mathrm{ml}$. solution containing $\mathrm{O} \cdot 1 \mathrm{~N}-\mathrm{H}_{2} \mathrm{SO}_{4}$ and $0.04 \mathrm{~N}-\mathrm{HCl}$.

c $3 \mu \mathrm{g} . \mathrm{Cu} / \mathrm{ml}$. solution containing $\mathrm{O} \cdot 1 \mathrm{~N}-\mathrm{H}_{2} \mathrm{SO}_{4}$ and $0.04 \mathrm{~N}-\mathrm{NaCl}$.

d $3 \mu \mathrm{g}$. $\mathrm{Cu} / \mathrm{ml}$. solution containing $0.1 \mathrm{~N}-\mathrm{H}_{2} \mathrm{SO}_{4}$ and 0.03 $\mathrm{N}-\mathrm{H}_{3} \mathrm{PO}_{4}$.

e $3 \mu \mathrm{g} . \mathrm{Cu} / \mathrm{ml}$. solution containing $0.1 \mathrm{~N}-\mathrm{H}_{2} \mathrm{SO}_{4}, 0.04$ $\mathrm{N}-\mathrm{NaCl}$, and $0.03 \mathrm{~N}-\mathrm{H}_{3} \mathrm{PO}_{4}$.

to be analysed was therefore $5 \mu \mathrm{g}$. and relatively large quantities of normal human blood, tissue, or urine were required for analysis, examples of which are shown in Table I. Under these conditions, the percentage recovery of copper added to the digestion stage was within the standard deviation obtained for standard copper curves (Fig. 1). Results obtained agreed closely with those reported previously (Butler and Newman, 1956).

In Wilson's disease (Wilson, 1912) the urinary excretion of copper is increased above normal (Uzman and Denny-Brown, 1948) and with the apparatus described it was possible to study the urinary copper excretion of a patient with Wilson's disease using quantities of urine suitable for rapid wet-ashing (Table I).

\section{CASE REPORT}

The patient, a boy (M.S.) aged 10 years 3 months (U.O.H. 215322), was admitted to the Radcliffe Infirmary, 
TABLE I

THE COPPER CONTENT OF HUMAN BLOOD AND URINE

Quantity of Material Taken for Analysis

No. of Subjects

$10 \mathrm{ml}$. heparinized blood (normal adult)

$250 \mathrm{ml}$. urine (normal adult)

$50 \mathrm{ml}$. urine (Wilson's disease, before treatment)

$25 \mathrm{ml}$. urine (Wilson's disease 1 week after treatment)

$25 \mathrm{ml}$. urine (Wilson's disease 3 weeks after treatment)

'Range

Oxford, under the care of Dr. Victoria Smallpeice. During the year before his admission he developed pruritus and later hepatic insufficiency. He presented the signs of loss of weight, massive ascites, corneal deposits (KayserFleischer rings), anaemia, impaired liver function tests,

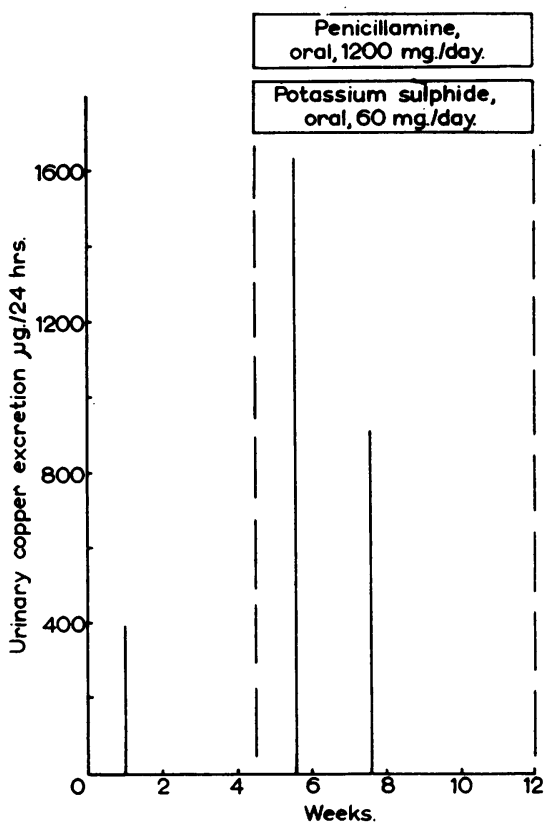

FIG. 3. The effect of penicillamine and potassium sulphide on the urinary excretion of copper. but no neurological abnormalities. The serum coppen was $43 \mu \mathrm{g} . / 100 \mathrm{ml}$. and the serum copper oxidase was $12 \mu 1.0_{2} / \mathrm{ml}$./hr. (Professor J. N. Cumings). The urinaryer copper output and the urinary amino-acid excretion were raised and of the type seen in Wilson's disease. He wasoo treated with a high-protein, low-salt diet, paracentesis abdominis, chlorothiazide with $\mathrm{KCl}$, spironolactone? and a blood transfusion. Urine, for copper analysis, was collected before and during treatment with penicillamine and potassium sulphide. The results (Fig. 3) are in agree-⿳亠二口犬 ment with those of Walshe (1956).

Three months after admission the patient had a severe $\overrightarrow{0}$ haematemesis and died. The post-mortem examination showed the bleeding was from oesophageal varices and that the liver was cirrhotic. Specimens of numerouso portions of brain tissue, liver, and kidney contained increased amounts of copper.

We are indebted to Mr. J. R. P. O'Brien for his encour ${ }^{\Omega}$ agement and advice, to Dr. Victoria Smallpeice for permission to quote clinical details of one of her patientso and to Professor J. N. Cumings and Dr. R. H. Wilkinson for biochemical data.

\section{REFERENCES}

Butler, E. J. (1952). Studies in the Determination and Biologica. Significance of Traces of Metals. Thesis for D.Phil. degree? University of Oxford.

and Newman, G. E. (1956). J. clin. Path, 9, 157

Margoshes, M., and Vallee, B. L. (1956). In Meth. biochem. Anal., 30 353, ed. by Glick, D. Interscience Publishers, New York and London.

Uzman, L., and Denny-Brown, D. (1948). Amer. J. med. Sci., 215음 599.

Walshe, J. M. (1956). Amer. J. Med., 21, 487.

Wilson, S. A. K. (1912). Brain, 34, 295. 